\title{
Antioxidant and anti-nociceptive effects of Phyllanthus amarus on improving exercise recovery in sedentary men: a randomized crossover (double-blind) design
}

\author{
Thapanee Roengrit ${ }^{1,5}$, Panakaporn Wannanon ${ }^{1,5}$, Piyapong Prasertsri ${ }^{2,5}$, Yupaporn Kanpetta, ${ }^{3,5}$, \\ Bung-orn Sripanidkulchai ${ }^{4,6}$ and Naruemon Leelayuwat ${ }^{1,5^{*}}$
}

\begin{abstract}
Background: Phyllanthus amarus (PA) is a herbal plant containing antioxidant compounds that scavenge free radicals. The reduced oxidative stress may decrease muscle damage leading to early recovery from muscle soreness. This study aimed to evaluate the effects of PA powder on oxidative stress, muscle damage, leukocyte counts, inflammation, and muscle soreness after a single bout of high-intensity exercise.

Methods: Twelve men participated in two 3-day phases separated by a 1-week washout in a randomized double-blinded, crossover design. On day 1, randomly divided participants ingested two capsules of either PA (PA group) or placebo (PLA group) 20 min before a single bout of cycling at high intensity for 20 min followed by four capsules (two capsules after lunch and dinner), and six capsules/day for the next 2 days. Blood samples were collected before, immediately after, and 24 and $48 \mathrm{~h}$ after the exercise. Pain threshold was measured at the mid-thigh on both legs.
\end{abstract}

Results: Malondialdehyde concentration in the PA group was lower than that in the PLA group $(p<0.05) 48 \mathrm{~h}$ after high-intensity exercise. Vitamin C concentration was greater in the PA than in the PLA group $(p<0.05)$ immediately after high-intensity exercise. Pain threshold in both legs in the PA group was higher than in the PLA group 24 and $48 \mathrm{~h}$ after high-intensity exercise. There were no significant differences in creatine kinase, leukocyte counts or inflammation between groups.

Conclusion: Acute PA supplementation reduced oxidative stress and muscle soreness induced by high-intensity exercise.

Keywords: Herbal plant, Pain threshold, Malondialdehyde, Vitamin C, Muscle damage, Leukocytes, Inflammation

\section{Introduction}

Physical inactivity is the fourth-greatest risk factor for global mortality [1] (World Health Organization [WHO]), because it is an important cause of noncommunicable diseases (NCDs) [2]. To prevent NCDs, WHO introduced the Global Recommendations on Physical Activity for Health [3], which encourage people of all ages to begin

\footnotetext{
* Correspondence: naruemon@kku.ac.th

${ }^{1}$ Department of Physiology, Faculty of Medicine, Khon Kaen University, Khon Kaen 40002, Thailand

${ }^{5}$ The Exercise and Sport Sciences Research and Development Group, Khon Kaen University, Khon Kaen 40002, Thailand

Full list of author information is available at the end of the article
}

moderately and gradually progress to higher levels of physical activity. Athletes often perform exercise at high intensity, aiming to win a competition. At the start of an exercise program, muscle damage both in sedentary participants [4] and athletes has often occurred [5]. Exercise-induced muscle damage is attributed to an exercise intensity-dependent increase in oxidative stress [6] produced by mitochondrial process (6). The oxidant damages the plasma membrane, which leads to leakage of creatine kinase (CK) into the blood [7]. This damage generates the inflammatory $\mathrm{C}$-reactive protein (CRP), which facilitates the influx of inflammatory cells to 
repair the damage [8]. Neutrophils and monocytes then repair the muscle via the oxidative or proteolytic modification to remove tissue debris in the injured muscle [9]. This process, known as the acute inflammatory response, causes muscle soreness after exercise [8]. Alternatively, the muscle soreness may be induced by increased hydrogen ion concentration or decreased $\mathrm{pH}$ of the muscle [10]. Rapid recovery from the prior exercise is important for both beginners performing regular exercise to improve their health and athletes preparing for competition. Thus, antioxidant supplementation to attenuate exercise-induced muscle injury, inflammation, and pain may facilitate success in both health promotion and sport competition.

Phyllanthus amarus (PA) is a herbal plant widely spread throughout tropical and subtropical areas, including in Thailand. PA extracts contain alkaloids, lignins, flavonoids, and polyphenol compounds [11]. These substances are known to have anti-carcinogenic and antiinflammatory properties [12], anti-nociceptive effects [13], and hematological and immunological properties [14].

Although eccentric exercise was shown to damage active muscle, concentric exercise was also reported to cause muscular damage [6]. The previous study demonstrated that the high intensity concentric exercise $(75 \%$ maximal oxygen consumption) increased CK activity immediately after the exercise. Moreover, the high-intensity exercise also increased neutrophil counts $24 \mathrm{~h}$ and monocyte counts $2 \mathrm{~h}$ after the exercise. These findings showed that the concentric exercise at high intensity causes the damage of active muscles and induces inflammation. Importantly, the reason for applying concentric exercise in this study is that we wanted to imitate real situation in daily life.

Thus far, no research investigating these effects of PA in exercise conditions in humans has been done; thus, we are interested in investigating its antioxidant, antiinflammatory, and anti-nociceptive effects on improving exercise recovery. To test the hypothesis that acute PA supplementation reduces pain during recovery from highintensity exercise, we examined the acute effects of PA on oxidative stress, muscle damage, leukocyte counts, inflammation, and muscle soreness after high-intensity exercise.

\section{Materials and methods Participants}

Twelve sedentary men aged $22 \pm 2.90$ years participated in the study. They did not perform regular vigorous exercise and had never taken antioxidant supplements or medications. Prior to enrollment in the study, each subject's physical examination and electrocardiogram (ECG) were taken. Blood samples were collected after a 12-h overnight fast to measure glucose, creatinine, lipid profiles, and alanine aminotransferase (ALT), to check subjects' health status prior to the study. None of the subjects was a smoker or had cardiovascular, renal, neuromuscular, orthopedic, or liver disease. This study was approved by the Khon Kaen University Ethical Committee and conformed to the standards set by the Declaration of Helsinki in 2010 (HE531029). All participants provided informed consent to participate in the study after receiving both verbal and written explanations.

\section{Power calculation}

The sample size of this study was calculated by the WINPEPI program by using the study of Fenercioglu et al. [15] which reported that the antioxidant supplement prevent the increased MDA after the exercise. It was decided to require $80 \%$ power at a significance level of 0.05 . Thus, the proposed size was 12 subjects per group.

\section{Study design}

This study was of a randomized crossover (double-blind) design. Subjects were blinded as to the composition of the PA and PLA or which supplement they were on at which times.

\section{Supplement preparation}

The supplements consisted of PA and placebo (PLA). The aerial parts of PA were collected from Khon Kaen Province. After washing with distilled water and drying at $50^{\circ} \mathrm{C}$, the plant was ground and tested for microbial contamination. The plant powder was then placed into capsules containing excipients. One PA capsule contained $100 \mathrm{mg}$ of dried PA powder and one placebo capsule contained Avicel ${ }^{\oplus} \mathrm{PH} 101$ (microcrystalline cellulose; FMC BioPolymer, Philadelphia, PA, USA), Aerosil ${ }^{\bullet}$ (desiccant; Evonik Industries, China), and artificial colors. Both supplements were manufactured and controlled the contents by the Center for Research and Development of Herbal Health Products, Khon Kaen University. They were produced in the same lot of manufacture. The dosage of the PA was based on recommendations for the product in Thailand (Khaolaor Laboratories Co. Ltd, G 357/42). The PA contents in each capsule consisted of total polyphenol $(33 \mathrm{mg} / \mathrm{g})$ and vitamin $\mathrm{C}(1.60 \mathrm{mg} / 100 \mathrm{~g})$ as measured by the Central Laboratory (Thailand) Co. Ltd., Thailand.

\section{Baseline measurements}

Before the experiment, anthropometric and body composition assessments were performed. Body composition was directly measured by Dual emission X-ray absorptiometry (DEXA) in the supine position. Fat distribution was indirectly measured by the ratio of waist and hip circumferences. A 3-day dietary and physical activity records were completed. 


\section{Peak oxygen consumption test}

Each participant underwent an incremental exercise test on the cycle ergometer (Corival, Lode, The Netherlands). Oxygen consumption and carbon dioxide production were measured throughout the test using a gas analysis system (AD instrument, ML206, Australia). The test was started with a 12 min 4-stage incremental test in which workload was increased every $3 \mathrm{~min}$ for 4 workloads [16]. The workload was determined from an estimate of the participants' physical fitness status. The peak oxygen uptake value $\left(\dot{\mathrm{V}}_{2, \text { peak }}\right)$ of the participant was determined when any of the following was achieved; the participant's $\dot{\mathrm{V}} \mathrm{O}_{2}$ reached a plateau with an increased workload, or a respiratory gas exchange ratio exceeded 1.15 , or the heart rate $(\mathrm{HR})$ reached a maximum $\mathrm{HR}$ (calculated by the equation: 220 - age), or maximal symptoms of dyspnea and fatigue by using the rating of perceived dyspnea (RPD) and the rating of perceived exertion (RPE) scales, or were unable to maintain cycling at a speed of $60 \mathrm{rpm}$. HR and ECG were continuously monitored during the test. After the participants reached the criteria, they rested, drank water, and measured their HR until it returned to normal. This test was done at least $1 \mathrm{wk}$ before the initial exercise session.

\section{Procedure}

Participants participated randomly in two 3-day visits 2 weeks apart to prevent carryover effect. At the start of all visits they randomly ingested two capsules of either PA or PLA 20 min before performing exercise on the cycle ergometer. They then exercised without a workload for a 3-min warm-up. They then exercised for 20 min at high intensity ( $85 \%$ of peak oxygen consumption). On the same day and for the next 2 days, participants received the same supplement they had taken initially (two capsules three times per day after meals). Blood samples were collected immediately before ingestion of the supplement, immediately before exercise, and 24 and $48 \mathrm{~h}$ after exercise.

\section{Blood chemistry}

At each visit, a 12-mL blood sample was taken from an antecubital vein. After placing $6 \mathrm{~mL}$ into EDTA, $2 \mathrm{~mL}$ into lithium heparin, and $4 \mathrm{~mL}$ into clotting tubes, all samples were placed immediately on ice. One EDTA tube $(2 \mathrm{~mL})$ was then added to $1 \mathrm{~mol} / \mathrm{L}$ of $\mathrm{HClO}_{4}$ to precipitate the protein to measure vitamin $\mathrm{C}$. All tubes were centrifuged at $4^{\circ} \mathrm{C}$ and $3,000 \mathrm{~g}$ for $15 \mathrm{~min}$. The upper layer was transferred to a microcentrifuge tube and stored at $-80^{\circ} \mathrm{C}$ until assay. CK, high-sensitivity CRP (hs-CRP), and complete blood count were analyzed in the clinical laboratory of the Srinagarind Hospital, Faculty of Medicine, Khon Kaen University, Thailand.

\section{Malondialdehyde (MDA) assay}

Plasma MDA, a marker of lipid peroxidation, was measured using the thiobarbituric acid (TBA) test according to the method of Draper [17]. The basis of the TBA method is the reaction of MDA with $0.6 \%$ of TBA at low $\mathrm{pH}$ and $95^{\circ} \mathrm{C}$ (boiled for $30 \mathrm{~min}$ ) to form a colored complex. Acid hydrolysis and heat are necessary for the release of MDA bound to the amino groups of proteins and other amino compounds. The MDA-TBA complex, with an absorption at $532 \mathrm{~nm}$, was measured using a spectrophotometer (Genesys 20, SN:35 gk 130009; Thermo Fisher Scientific, Waltham, MA, USA).

\section{Vitamin C assay}

Plasma vitamin $\mathrm{C}$ concentration was measured by using Zhang's method [18]. In this assay, $\mathrm{Fe}(\mathrm{III})$ is deoxidized to $\mathrm{Fe}(\mathrm{II})$ by ascorbate at $\mathrm{pH} 4.0$ and $\mathrm{Fe}(\mathrm{II})$ reacts with potassium ferricyanide to form a blue product, soluble Prussian blue $\left(\mathrm{KFe}^{\mathrm{III}}\left[\mathrm{Fe}^{\mathrm{II}}(\mathrm{CN})_{6}\right]\right)$. The absorbance of this product was monitored over time using a spectrophotometer at $735 \mathrm{~nm}$ and the amount of ascorbate was calculated based on absorbance.

\section{Nitric oxide ( $\mathrm{NO}^{\circ}$ ) assay}

Plasma NO concentration was measured indirectly using inNO Nitric Oxide Measuring System and Sensors (Innovative Instruments, Inc., Brooks Court, FL, USA). The generation of $\mathrm{NO}^{\prime}$ is achieved by the addition of standard nitrite solution to an acidified solution in the presence of a reducing agent such as iodide ion according to the following equation:

$$
2 \mathrm{NO}_{2}^{-}+2 \mathrm{I}^{-}+4 \mathrm{H}^{+} \rightarrow 2 \mathrm{NO}^{-}+\mathrm{I}_{2}+2 \mathrm{H}_{2} \mathrm{O}
$$

As shown in the chemical equation, the molar ratio of nitrite to nitric oxide is 1:1. Thus, the amount of nitric oxide generated equals the amount of nitrite added.

\section{Muscle damage}

To determine the degree of muscle damage, serum CK activity was assessed. It is proportional to the rate of NADPH formation and was measured with a Roche/Hitachi $\operatorname{cobas}^{\circ} \mathrm{C}$ 502 analyzer (Roche, Basel, Switzerland) using standard automated laboratory methods.

\section{Inflammation}

CK activity and hsCRP concentration were determined using a Roche/Hitachi cobas c system (Cobas c 501, Roche Diagnostics, Indianapolis, IN, USA). The principle of CK activity measurement was the rate of the NADPH formation, which is directly proportional to the catalytic CK activity. It is determined by measuring the increase in absorbance. Equimolar quantities of NADPH and ATP are formed at the same rate. The photometrically measured 
rate of formation of NADPH is directly proportional to the CK activity. HsCRP level was determined using a particle enhanced immuno-turbidimetric assay method, in that agglutinates formation of human CRP with latex particles coated with monoclonal anti-CRP antibody was determined turbidimetrically.

\section{Muscle soreness}

Muscle soreness was measured by the pressure pain threshold of the quadriceps muscle at the mid-thigh using an algometer. Participants were asked to indicate verbally when they felt pain from the pressure.

\section{Statistics}

Data are presented as mean \pm SD except when stated otherwise. Dependent variables were analyzed using repeated measure analysis of variance (ANOVA). Statistical analysis was performed using SPSS statistical software, version 18 (SPSS, Chicago, IL, USA). For all statistical tests, differences were considered significant when the $p$ value was less than 0.05 .

\section{Results}

\section{Participant characteristics}

The participants in this study were 12 healthy sedentary men. Anthropometry and physical fitness are summarized in Table 1. Baseline blood parameters are shown in Table 2. Regarding percentage of peak oxygen consumption, all participants performed exercise at high intensity (80.62 \pm $3.3 \%$ and $82.39 \pm 7.0 \% \dot{V O}_{2 \text {,peak }}$ for PLA and PA groups, respectively). In addition, participants' dietary composition, energy intake, and energy expenditure are presented

Table 1 Anthropometry, body composition and physical fitness of participants

\begin{tabular}{lc}
\hline & Mean \pm SD \\
\hline Age $(\mathrm{yr})$ & $22 \pm 2.9$ \\
Height $(\mathrm{m})$ & $1.69 \pm 0.06$ \\
$\mathrm{BM}(\mathrm{kg})$ & $63.6 \pm 10.7$ \\
$\mathrm{BMI}\left(\mathrm{kg} / \mathrm{m}^{2}\right)$ & $22.8 \pm 3.3$ \\
\%BF & $19.5 \pm 9.0$ \\
FM (kg) & $12.5 \pm 7.3$ \\
FFM (kg) & $48.4 \pm 6.6$ \\
Waist circumference (cm) & $76.7 \pm 7.5$ \\
Hip circumference (cm) & $94.8 \pm 6.1$ \\
Waist: hip circumference ratio & $0.81 \pm 0.04$ \\
Physical fitness & \\
$\dot{\text { VO }}$ 2,peak (ml/kgBM/min) & $36.9 \pm 5.2$ \\
Work load & $136.0 \pm 32.4$ \\
\hline Values
\end{tabular}

Values are presented as mean $\pm S D ; n=12$.

$\mathrm{BM}$, body mass; $\mathrm{BMI}$, body mass index; \%BF, percentage of body fat; $\mathrm{FM}$, fat mass; FFM, fat free mass; $\dot{V}_{2}$,peak, peak oxygen consumption.
Table 2 Baseline blood parameters of participants

\begin{tabular}{lc}
\hline & Mean \pm SD \\
\hline Blood glucose $(\mathrm{mM})$ & $4.6 \pm 0.3$ \\
Creatinine $(\mu \mathrm{mol} / \mathrm{L})$ & $0.01 \pm 0.001$ \\
ALT $(\mathrm{IU} / \mathrm{L})$ & $23.08 \pm 24.91$ \\
TG $(\mathrm{mM})$ & $1.1 \pm 0.3$ \\
TC $(\mathrm{mM})$ & $2.6 \pm 1.4$ \\
LDL $(\mathrm{mM})$ & $2.8 \pm 0.9$ \\
HDL $(\mathrm{mM})$ & $1.6 \pm 0.4$ \\
\hline
\end{tabular}

Values are presented as mean $\pm \mathrm{SD} ; \mathrm{n}=12$.

TG, triglycerides; TC, total cholesterol; LDL, low density lipoprotein; HDL, high density lipoprotein; ALT, alanine aminotransferase.

in Table 3. Physiological parameters, dietary composition (including vitamin C), energy intake, and energy expenditure were not different between groups.

\section{Muscle soreness}

The pain thresholds of both legs were lower at $24 \mathrm{~h}$ and $48 \mathrm{~h}(\mathrm{p}<0.05)$ after the high-intensity exercise in the PLA group than in the PA group (Figure 1A and 1B). In addition, the pain threshold of the right leg was lower 48 $\mathrm{h}$ after high-intensity exercise than pre-exercise in the PLA group (Figure 1A).

\section{Oxidative stress, damage and inflammation}

Plasma MDA concentration in the PA group was significantly lower than that of the PLA group $48 \mathrm{~h}$ after highintensity exercise $(1.92 \pm 0.53$ vs. $3.44 \pm 1.27 \mathrm{nM} ; \mathrm{p}<0.01)$ (Figure 2). Vitamin $C$ concentration was significantly

Table 3 Dietary composition, energy intake and energy expenditure of participants

\begin{tabular}{lll}
\hline \multicolumn{2}{l}{ PLA } & PA \\
\hline Dietary composition (/day) & & \\
- Protein (g) & $122.9 \pm 30.6$ & $125.4 \pm 35.6$ \\
- Fat (g) & $89.3 \pm 30.2$ & $78.0 \pm 17.4$ \\
- Carbohydrate (g) & $254.3 \pm 71.7$ & $239.2 \pm 62.9$ \\
- Fiber (g) & $5.6 \pm 2.0$ & $7.1 \pm 2.1$ \\
- Vitamin C (mg) & $23.2 \pm 18.4$ & $27.1 \pm 12.2$ \\
- Vitamin A (RE) & $746.1 \pm 1388.8$ & $710.4 \pm 1382.4$ \\
- Thiamine (mg) & $1.3 \pm 0.4$ & $1.2 \pm 0.5$ \\
- Riboflavin (mg) & $1.9 \pm 1.0$ & $1.4 \pm 0.5$ \\
- Niacin (mg) & $20.7 \pm 6.6$ & $18.6 \pm 6.5$ \\
$\begin{array}{ll}\text { Energy intake (kcal/day) } \\
\text { Energy expenditure (kcal/day) }\end{array}$ & $2289.2 \pm 475.8$ & $2112.0 \pm 423.2$ \\
\hline $\begin{array}{l}\text { Values are presented as mean } \pm \text { SD; } \mathrm{n}=12 . \\
\text { Vitamin A 1 RE = 12 } \mu \text { g alpha-carotene. }\end{array}$ & \\
$\begin{array}{l}\text { PLA, placebo group; PA, Phyllanthus amarus group; RE, retinol equivalent; kcal, } \\
\text { kilocalories; g, grams; mg, milligrams; kg, kilograms. }\end{array}$ & \\
& & $2127.9 \pm 654.6$ \\
\hline
\end{tabular}



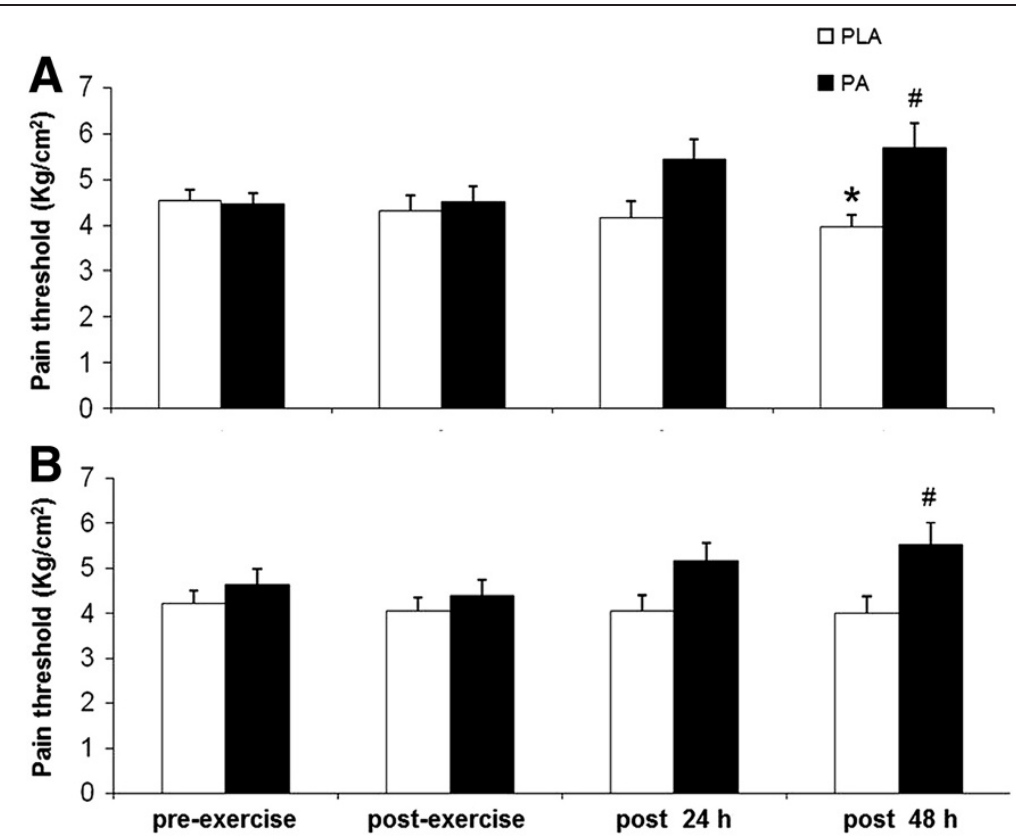

Figure 1 Levels of pain threshold on the right leg (A) and left leg (B) before exercise (pre-exercise), immediately after (post-exercise), and $24 \mathrm{~h}$ (post $24 \mathrm{~h}$ ) and $\mathbf{4 8} \mathrm{h}$ (post $\mathbf{4 8} \mathrm{h}$ ) after high-intensity exercise. Values are presented as mean \pm SE $(n=12)$. PLA, placebo. *Significantly different from before exercise $(p<0.05)$, \#significantly different from the PLA group at the same time point $(p<0.05)$.

higher in the PA group than in the PLA group immediately after high-intensity exercise $(9.68 \pm 2.21$ vs. $5.91 \pm 1.45 \mu \mathrm{g} /$ $\mathrm{mL} ; \mathrm{p}<0.05$ ) (Figure 3). It then fell to baseline at $24 \mathrm{~h}$ after exercise. Plasma CK concentration were significantly higher immediately after exercise than before exercise (Table 4). However, $\mathrm{CK}, \mathrm{NO}^{\circ}$ and hs-CRP concentrations were not significantly different between groups at any time point (Table 4).

\section{Leukocyte counts}

Neutrophil count was significantly higher immediately after exercise than before exercise in both groups (Table 4). Neutrophil count at $24 \mathrm{~h}$ was significantly lower than immediately after exercise in the PA group $(\mathrm{p}<0.05)$ (Table 4). Lymphocyte count significantly increased immediately after exercise when compared with pre-exercise $(\mathrm{p}<0.05)$ (Table 4). Moreover lymphocyte counts at $48 \mathrm{~h}$

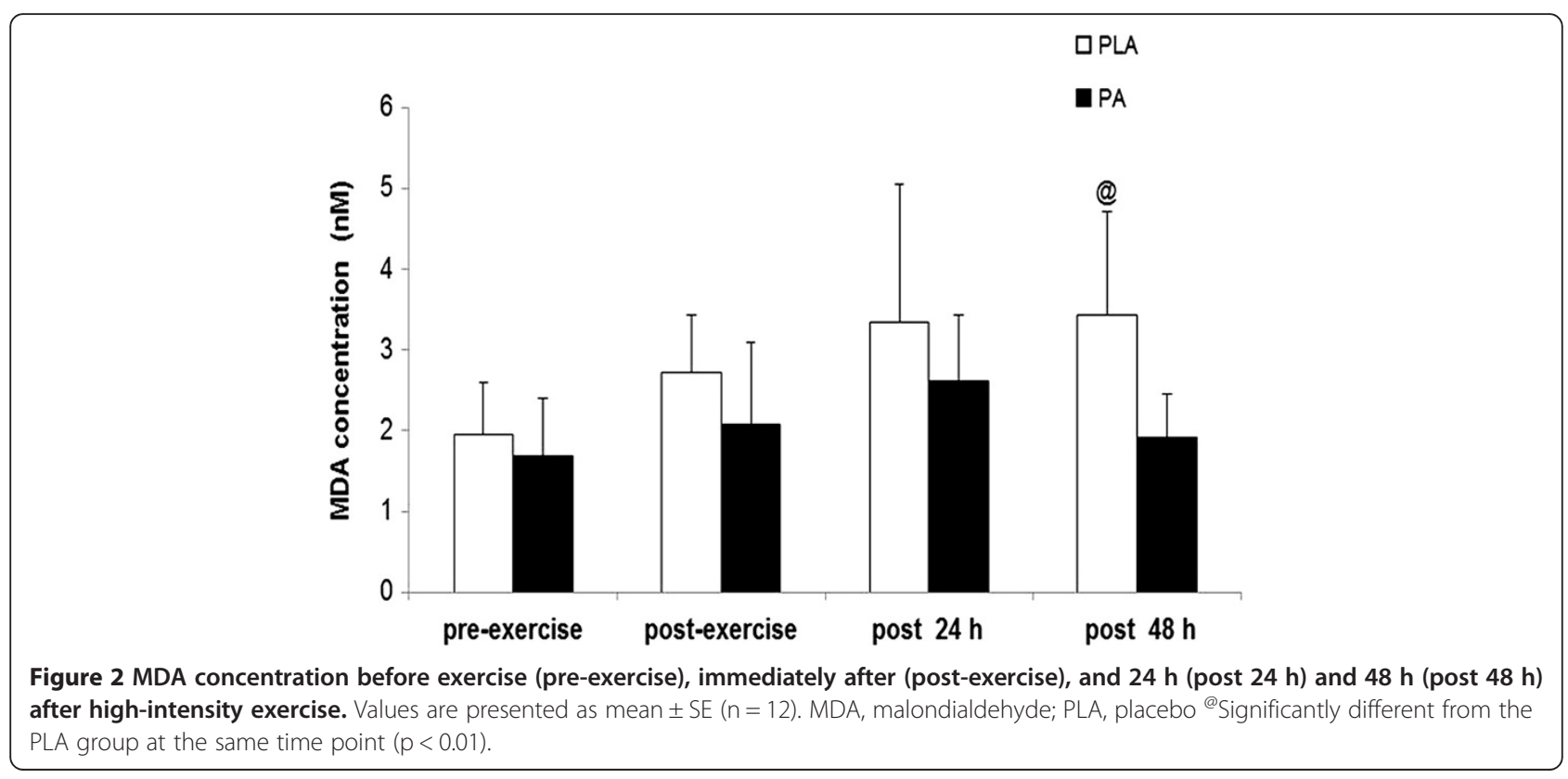




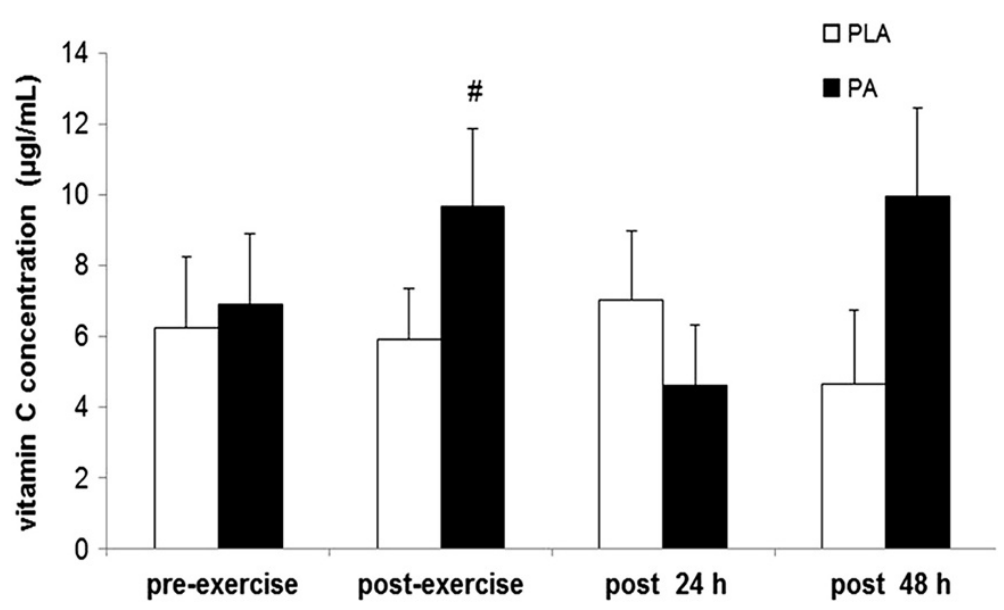

Figure 3 Vitamin C concentration before exercise (pre-exercise), immediately after (post-exercise), and $24 \mathrm{~h}$ (post $24 \mathrm{~h}$ ) and $48 \mathrm{~h}$ (post $48 \mathrm{~h})$ after high-intensity exercise. Values are presented as mean $\pm S E(n=12)$. PLA, placebo. \#Significantly different from the PLA group at the same time point $(p<0.05)$.

in the PA group and $24 \mathrm{~h}$ in the PLA group significantly lower than immediately after the exercise $(\mathrm{p}<0.05)$ (Table 4). Monocyte count was significantly increased $24 \mathrm{~h}$ after the exercise when compared with pre-exercise $(\mathrm{p}<0.05)$ (Table 4). There were no significant betweengroup differences in leukocyte count at any time point.

\section{Discussion}

Our results demonstrate that acute PA supplementation may reduce the muscle soreness of both legs during recovery from high-intensity exercise in healthy participants.

The results partially support our hypothesis that acute PA supplementation reduces pain during recovery from highintensity exercise. Previous studies on PA supplementation have demonstrated the antioxidant and anti-nociceptive effects of PA in animals under non-exercise conditions [19-21]. Thus, the present study is the first to demonstrate a reduction in muscle pain after the ingestion of PA immediately before and a few days after the exercise with improved oxidative stress during recovery. A review of the literature suggests that muscle soreness is strongest 24-72 $\mathrm{h}$ after exercise [22]. Our finding of decreased muscle soreness at $24 \mathrm{~h}$ may demonstrate a potential effect of PA on recovery from muscle soreness and may enable beginners in sports activity to return to a competition or an exercise session the next day.

PA has been shown by this study to contain a wide variety of antioxidant compounds, such as vitamin $\mathrm{C}$ and total polyphenol compounds. The lack of difference in dietary vitamin $\mathrm{C}$ intake before the experiment between

Table 4 CK, NO', hs-CRP concentrations and leukocyte counts before the exercise (pre-exercise), immediately (post-exercise), $24 \mathrm{~h}$ (post $24 \mathrm{~h}$ ) and $48 \mathrm{~h}$ (post $48 \mathrm{~h}$ ) after the high-intensity exercise

\begin{tabular}{llllll}
\hline & & Pre-exercise & Post-exercise & Post-24 h & Post-48 h \\
\hline CK $(\mathrm{U} / \mathrm{L})$ & PLA & $151.8 \pm 22.4$ & $166.0 \pm 24.9^{*}$ & $164.8 \pm 25.2$ & $163.7 \pm 30.1$ \\
& PA & $132.3 \pm 19.0$ & $194.5 \pm 21.5^{*}$ & $182.6 \pm 41.5$ & $145.6 \pm 65.6$ \\
hs-CRP $(\mathrm{mg} / \mathrm{L})$ & PLA & $1.24 \pm 0.37$ & $1.36 \pm 0.43$ & $1.58 \pm 0.74$ & $1.28 \pm 1.11$ \\
& PA & $1.24 \pm 0.33$ & $1.15 \pm 0.33$ & $4.05 \pm 0.53$ & $3.26 \pm 0.42$ \\
Neutrophils $\left(10^{3} / \mathrm{\mu L}\right)$ & PLA & $3.68 \pm 0.33$ & $4.80 \pm 0.61^{*}$ & $3.09 \pm 0.25 \infty$ & $3.37 \pm 0.26$ \\
& PA & $3.53 \pm 0.35$ & $4.39 \pm 0.45^{*}$ & $1.77 \pm 0.08 \infty$ & $1.75 \pm 0.10$ \\
Lymphocytes $\left(10^{3} / \mu \mathrm{L}\right)$ & PLA & $2.08 \pm 0.19$ & $2.57 \pm 0.39$ & $2.13 \pm 0.15$ & $1.94 \pm 0.09 \infty$ \\
& PA & $1.88 \pm 0.16$ & $2.61 \pm 0.28^{*}$ & $0.44 \pm 0.06$ & $0.43 \pm 0.03$ \\
Monocytes $\left(10^{3} / \mathrm{mL}\right)$ & PLA & $0.41 \pm 0.02$ & $0.45 \pm 0.05$ & $0.48 \pm 0.33 \infty$ & $0.44 \pm 0.06$ \\
\hline
\end{tabular}

Values are presented as mean $\pm \mathrm{SE} ; \mathrm{n}=12$.

NO, nitric oxide; hs-CRP, high sensitive C-reactive protein.

*Significantly different from before the high-intensity exercise $(p<0.05)$.

$\infty$ Significantly different from immediately after the exercise (post-exercise) $(p<0.05)$. 
the groups confirmed that the greater plasma vitamin $\mathrm{C}$ concentration was induced by the PA supplementation. The amount of vitamin $\mathrm{C}$ in the PA intake per day in this study seemed to be too small to increase plasma vitamin $\mathrm{C}$ concentration. In a previous study, vitamin $\mathrm{C}$ intake of less than $200 \mathrm{mg}$ ( $9.60 \mathrm{mg}$ in this study) increased the absorption rate to $98 \%$ [23]. This may contribute to the higher vitamin $\mathrm{C}$ concentration immediately after the exercise in the PA than the placebo group. Apart from vitamin $\mathrm{C}$, the PA in each capsule contains $33 \mathrm{mg} / \mathrm{g}$ of total polyphenol. Although polyphenol compounds in participants' blood were not measured in this study, it may play antioxidant role during and immediately after the exercise. Polyphenol may spare the antioxidant activity of vitamin $\mathrm{C}$ at this period. Then the decreased vitamin $\mathrm{C}$ concentration at the following $24 \mathrm{~h}$ after the exercise may imply that vitamin $\mathrm{C}$ was greatly consumed in scavenging free radicals resulting in the decrease of lipid peroxidation indicated by MDA at $48 \mathrm{~h}$ after the exercise.

In addition, three possible mechanisms explaining important anti-nociceptive role of vitamin $\mathrm{C}$ and total polyphenol compounds induced by PA supplementation are: 1) stimulation of the secretion of beta-endorphin by vitamin $\mathrm{C}$, which is effective at reducing neuropathic pain $[24], 2)$ scavenging reactive oxygen species [25], which play an important role in reducing neuropathic pain [26]. The reduction in free radicals resulted in decreased prostaglandins [27], which are sympathetic nervous system pain mediators [28], as well as by central inhibitory pain mechanisms [29]. Unfortunately, beta-endorphin secretion and the pain mediators are not examined by this study. Therefore, the effects of acute PA supplementation on either beta-endorphin secretion or the liberation of pain mediators should be further investigated. 3) Reduction in hydrogen ion produced by high-intensity exercise may be one of the mechanisms that explain the effect of these antioxidants on pain reduction. Proton normally produced by high-intensity exercise was shown to increase pain and fatigue [30]. Recently polyphenol including flavonoid was demonstrated to scavenge free radicals by hydrogen ion transfer. This may thus reduce noxious effects due to oxidative stress [31].

The anti-nociceptive effect of antioxidants mentioned above was shown in non-exercise condition. This effect on exercise recovery in humans is still unclear. Some authors have reported reductions in muscle pain [32], but others did not demonstrate this effect [33,34]. The discrepancy may be due to the duration and timing of supplementation. The anti-nociceptive effect seems to be present if PA is ingested long before the exercise (>2 wk) $[32,35,36]$ because this finding is not reported in previous studies with shorter durations of preexercise ( $2 \mathrm{~h}$ to $3 \mathrm{~d}$ ) and post-exercise supplementation [33,34,37-39].
The significant increase in plasma CK concentration indicated increased muscle damage, as determined by both supplement groups immediately after the high-intensity exercise. This indicates that the single bout of high-intensity exercise for $20 \mathrm{~min}$ in this study was sufficient to cause muscle damage. However, we did not find any difference in CK concentration between groups, which, combined with the lack of differences in immune cell counts and inflammatory responses to the exercise between groups suggests that the development of cell damage and inflammation in this exercise was not attenuated by PA supplementation.

Improved oxidative stress after exercise by PA supplementation might be useful for some medical conditions generating high oxidative stress, such as type 2 diabetes mellitus [40] or for individuals with pre-hypertension who got benefit effect from the reduced oxidative stress [41] but further study would be required to prove this possibility. It is likely that acute supplementation during exercise may provide protection until patients can adapt to oxidative stress by modifying their own antioxidant status, which require a bit of time. Moreover, prolonged supplementation before exercise may provide protective effects against oxidative stress and exercise recovery in the patients who are not trained person.

We performed our research according to the guidelines proposed by a recent review article on studies investigating the impact of antioxidant supplementation on exercise performance [42] by carefully preparing and storing the antioxidant compounds; i.e., PA in this study, to prevent oxidation and degradation. Also, to ensure that the results in this study were really due to the PA ingested, we compared the dietary status of both groups and confirmed no difference between them. Moreover, the subjects had no other antioxidant supplementation at any time before or during the experiment.

A limitation of this study is that the dose of PA powder was the dose for resting conditions. This was intended to avoid adverse effects on participants. A longer duration of PA supplementation before exercise, or a higher dose of PA, might be required to yield muscle damage and inflammation and greater and earlier beneficial effects on muscle soreness after high-intensity exercise, which in turn may contribute to rapid recovery after high-intensity exercise.

\section{Conclusions}

The present study shows that PA supplementation improved oxidative stress and muscle soreness induced by high-intensity exercise. This may encourage beginners or novices in sports activity or fitness to return to a competition or an exercise session the next day, with early recovery from muscle soreness. The present results add a treatment value of PA, a herb generally found in Thailand, in aspects of both health and sport. 


\section{Abbreviations}

ALT: Alanine aminotransferase; ANOVA: Analysis of variance; CK: Creatine kinase; ECG: Electrocardiogram; DEXA: Dual emission x-ray absorptiometry; EDTA: Ethylene diamine tetra acetic acid; HDL: High-density lipoprotein; hs CRP: high sensitive C reactive protein; MDA: Malondialdehyde; NO: Nitric oxide; NCDs: noncommunicable diseases; PA: Phyllanthus amarus; PLA: Placebo; RE: retinol equivalent; TBA: Thiobarbituric acid; $\dot{V}_{2, \text { peak: }}$ Peak oxygen consumption; WHO: World Health Organization.

\section{Competing interests}

The authors declare that they have no competing of interest.

\section{Authors' contributions}

NL conceived and designed the study and prepared the manuscript. PW provided medical coverage throughout the experiment. TR carried out all the experimental work and statistical analysis and helped to draft the manuscript. PP and YK assisted the experimental work. BS provided PA and PLA supplements. All authors read and approved the final manuscript.

\section{Acknowledgments}

This study was supported by the Graduate Research Fund Academic Year 2010 (53212102) Khon Kaen University, National Research University (MIH-2554-Ph.D-10), and Invitation research (I 55145). It was partially supported by the Exercise and Sport Sciences Research and Development Group and Back, Neck and Other Joint Pain Research Group, Khon Kaen University. We thank the Center for Research and Development of Herbal Health Products, Khon Kaen University, for the supplement manufacture. We thank Professor Yukifumi Nawa for his excellent proofreading of this manuscript. Finally, we thank the volunteers for their enthusiastic participation in this study.

\section{Author details}

'Department of Physiology, Faculty of Medicine, Khon Kaen University, Khon Kaen 40002, Thailand. ${ }^{2}$ Faculty of Allied Health Sciences, Burapha University, Chonburi 20130, Thailand. ${ }^{3}$ Exercise and Sport Sciences Program, Graduate School, Khon Kaen University, Khon Kaen 40002, Thailand. ${ }^{4}$ Faculty of Pharmaceutical Sciences, Khon Kaen University, Khon Kaen 40002, Thailand. ${ }^{5}$ The Exercise and Sport Sciences Research and Development Group, Khon Kaen University, Khon Kaen 40002, Thailand. ${ }^{6}$ The Center for Research and Development of Herbal Health Products, Khon Kaen University, Khon Kaen 40002, Thailand.

Received: 14 December 2013 Accepted: 13 March 2014

Published: 17 March 2014

\section{References}

1. World Health Organization: Global health risks: mortality and burden of disease attributable to selected major risks. Geneva: World Health Organization Press; 2009

2. World Health Organization: The global burden of disease: 2004 update. Geneva: World Health Organization Press; 2008.

3. World Health Organization: Global recommendations on physical activity for health. Geneva. ISBN 9789241599979. 2010.

4. Moflehi D, Kok LY, Tengku-Kamalden TF, Amri S: Effect of single-session aerobic exercise with varying intensities on lipid peroxidation and muscle-damage markers in sedentary males. Glob J Health Sci 2012, 4:48-54. doi:10.5539/gjhs.v4n4p48.

5. Teixeira VH, Valente HF, Casal SI, Marques FP, Moreira PA: Blood antioxidant and oxidative stress biomarkers acute responses to a 1000-m kayak sprint in elite male kayakers. J Sports Med Phys Fitness 2013, 53:71-79.

6. Seifi-Skishahr F, Siahkohian M, Nakhostin-Roohi B: Influence of aerobic exercise at high and moderate intensities on lipid peroxidation in untrained men. J Sports Med Phys Fitness 2008, 48:515-521.

7. Brancaccio P, Maffulli N, Limongelli FM: Creatine kinase monitoring in sport medicine. Br Med Bull 2007, 81-82:209-230.

8. Semple SJ, Smith LL, McKune AJ, Neveling N, Wadee A: Alterations in acute-phase reactants (CRP, rheumatoid factor, complement, Factor B, and immune complexes) following an ultramarathon. SA Sports Medicine 2004, 16:17-21.

9. Nieman DC: Immune response to heavy exertion. J Appl Physiol 1997, 82:1385-1394.
10. Issberner U, Reeh PW, Steen KH: Pain due to tissue acidosis: a mechanism for inflammatory and ischemic myalgia? Neurosci Lett 1996, 208:191-194.

11. Kumaran A, Karunakaran RJ: In vitro antioxidant activities of methanol extracts of five Phyllanthus species from India. LWT. Food Sci Technol 2007, 40:344-352. DOl:10.1016/j.Iwt.2005.09.011

12. Kiemer AK, Hartung T, Huber C, Vollmar AM: Phyllanthusamarus has anti-inflammatory potential by inhibition of iNOS, COX-2, and cytokines via the NF-kappaB pathway. J Hepatol 2003, 38:289-297.

13. Santos AR, Filho VC, Yunes RA, Calixto JB: Analysis of the mechanisms underlying the antinociceptive effect of the extracts of plants from the genus Phyllanthus. Gen Pharmacol 1995, 26:1499-1506.

14. Taiwo IA, Oboh BO, Francis-Garuba PN: Haematological properties of aqueous extracts of Phyllantus amarus (Schum and Thonn.) and Xylopia aethiopica (Dunal) A. Rich in albino rats. Ethno-Med 2009, 3:99-103.

15. Fenercioglu AK, Saler T, Genc E, Sabuncu H, Altuntas Y: The effects of polyphenol-containing antioxidants on oxidative stress and lipid peroxidation in Type 2 diabetes mellitus without complications. J Endocrinol Invest 2010, 33:118-124. doi:10.3275/6564. Epub 2009 Oct 15.

16. Prasertsri $P$, Roengrit $T$, Kanpetta $Y$, Tong-un T, Muchimapura S, Wattanathorn J, Leelayuwat N: Cashew apple juice supplementation enhanced fat utilization during high-intensity exercise in trained and untrained men. I Int Soc Sports Nutr 2013, 10:13. doi:10.1186/1550-2783-10-13.

17. Draper HH, Squires EJ, Mahmoodi H, Wu J, Agarwal S, Hadley M: A comparative evaluation of thiobarbituric acid methods for the determination of malondialdehyde in biological materials. Free Radic Biol Med 1993, 15:353-363.

18. Zhang H, Li J, Wang K, Du X, Li Q: A simple and sensitive assay for ascorbate using potassium ferricyanide as spectroscopic probe reagent. Anal Biochem 2009, 388:40-46.

19. Karuna R, Reddy SS, Baskar R, Saralakumari D: Antioxidant potential of aqueous extract of Phyllanthusamarus in rats. Indian J Pharmacol 2009, 41:64-67. doi:10.4103/0253-7613.51342.

20. Maity S, Chatterjee S, Variyar PS, Sharma A, Adhikari S, Mazumder S: Evaluation of antioxidant activity and characterization of phenolic constituents of Phyllanthusamarus root. J Agric Food Chem 2013, 61:3443-3450.

21. Obidike IC, Salawu OA, Ndukuba M, Okoli CO, Osunkwo UA: The anti-inflammatory and antinociceptive properties of the chloroform fraction from Phyllanthusniruri plant is mediated via the peripheral nervous system. J Diet Suppl 2010, 7:341-350. doi:10.3109/19390211.2010.522553.

22. Nosaka K: Muscle soreness and damage and the repeated-bout effect. In Skeletal muscle damage and repair 2008 (pp. 63). Edited by Tiidus PM. Champaign, IL: Human Kinetics. ISBN 978-0-7360-5867-4.

23. Levine M, Conry-Cantilena C, Wang Y, Welch RW, Washko PW, Dhariwal KR, Park JB, Lazarev A, Graumlich JF, King J, Cantilena LR: "Vitamin C pharmacokinetics in healthy volunteers: evidence for a recommended dietary allowance". Proc Natl Acad Sci USA 1996, 93:3704-3709. Bibcode:1996PNAS...93.3704L. doi:10.1073/pnas.93.8.3704.

24. Yang Z, Copolov DL, Lim AT: Ascorbic acid augments the adenylyl cyclase-cAMP system mediated POMC mRNA expression and beta-endorphin secretion from hypothalamic neurons in culture. $\mathrm{Br}$ Res 1996, 706:243-248

25. Rice ME: Ascorbate regulation and its neuroprotective role in the brain. Trends Neurosci 2000, 23:209-216.

26. Kim HK, Park SK, Zhou JL, Taglialatela G, Chung K, Coggeshall RE, Chung JM: Reactive oxygen species (ROS) play an important role in a rat model of neuropathic pain. Pain 2004, 111:116-124.

27. Ye Y, Guo Y, Luo YT: Anti-inflammatory and analgesic activities of a novel biflavonoid from shells of Camellia oleifera. Int J Mol Sci 2012, 13:12401-12411. doi:10.3390/ijms131012401.

28. Duarte JDG, Nakamura M, Ferreira SH: Participation of the sympathetic system in acetic acid induced writhing in mice. Braz J Med Biol Res 1988 21:341-343.

29. Ren W, Kiritoshi T, Gregoire S, Ji G, Guerrini R, Calo G, Neugebauer V: Neuropeptide S: a novel regulator of pain-related amygdala plasticity and behaviors. J Neurophysiol 2013, 110:1765-1781. doi:10.1152/ jn.00874.2012. Epub 2013 Jul 24.

30. Pollak KA, Swenson JD, Vanhaitsma TA, Hughen RW, Jo D, Light KC, Schweinhardt P, Amann M, Light AR: Exogenously applied muscle metabolites synergistically evoke sensations of muscle fatigue and pain in human subjects. Exp Physiol 2014, 99:368-380. doi:10.1113/ expphysiol.2013.075812. Epub 2013 Oct 18. 
31. Di Meo F, Lemaur V, Cornil J, Lazzaroni R, Duroux JL, Olivier $Y$, Trouillas $P$ : Free radical scavenging by natural polyphenols: atom versus electron transfer. J Phys Chem A 2013, 117:2082-2092. doi:10.1021/jp3116319. Epub 2013 Mar 5.

32. Bloomer RJ, Goldfarb AH, McKenzie MJ, You T, Nguyen L: Effects of antioxidant therapy in women exposed to eccentric exercise. Int I Sport Nutr Exerc Metab 2004, 14:377-388.

33. Close GL, Ashton T, Cable T, Doran D, Holloway C, McArdle F, MacLaren DP: Ascorbic acid supplementation does not attenuate post-exercise muscle soreness following muscle-damaging exercise but may delay the recovery process. Br J Nutr 2006, 95:976-981.

34. Thompson D, Williams C, Garcia-Roves P, McGregor SJ, McArdle F, Jackson MJ: Post-exercise vitamin C supplementation and recovery from demanding exercise. Eur J Appl Physiol, 89:393-400. Epub 2003 Apr 1.

35. Bryer SC, Goldfarb AH: Effect of high dose vitamin C supplementation on muscle soreness, damage, function, and oxidative stress to eccentric exercise. Int J Sport Nutr Exerc Metab 2006, 16:270-280.

36. Thompson D, Williams C, McGregor SJ, Nicholas CW, McArdle F, Jackson MJ, Powell JR: Prolonged vitamin C supplementation and recovery from demanding exercise. Int J Sport Nutr Exerc Metab 2001, 11:466-481.

37. Thompson D, Williams C, Kingsley M, Nicholas CW, Lakomy HK, McArdle F, Jackson MJ: Muscle soreness and damage parameters after prolonged intermittent shuttle-running following acute vitamin $\mathrm{C}$ supplementation. Int J Sports Med 2001, 22:68-75.

38. Childs A, Jacobs C, Kaminski T, Halliwell B, Leeuwenburgh C Supplementation with vitamin $\mathrm{C}$ and $\mathrm{N}$-acetyl-cysteine increases oxidative stress in humans after an acute muscle injury induced by eccentric exercise. Free Radic Biol Med 2001, 31:745-753.

39. Connolly DA, Lauzon C, Agnew J, Dunn M, Reed B: The effects of vitamin C supplementation on symptoms of delayed onset muscle soreness. J Sports Med Phys Fitness 2006, 46:462-467.

40. Leelayuwat N, Tunkumnerdthai O, Donsom M, Punyaek N, Manimanakorn A, Kukongviriyapan U, Kukongviriyapan V: An alternative exercise and its beneficial effects on glycaemic control and oxidative stress in participants with type 2 diabetes. Diabetes Res Clin Pract 2008, 82:e5-e8.

41. Wichitsranoi J, Weerapreeyakul N, Boonsiri P, Settasatian C, Settasatian N, Komanasin N, Sirijaichingkul S, Teerajetkul Y, Jungtrakul D, Leelayuwat N: Antihypertensive and antioxidant effects of dietary black sesame meal in pre-hypertensive humans. Nutr J 2011, 9:10-82.

42. Powers SK, Smuder AJ, Kavazis AN, Hudson MB: Experimental guidelines for studies designed to investigate the impact of antioxidant supplementation on exercise performance. Int I Sport Nutr Exerc Metab 2010, 20:2-14

doi:10.1186/1550-2783-11-9

Cite this article as: Roengrit et al: Antioxidant and anti-nociceptive effects of Phyllanthus amarus on improving exercise recovery in sedentary men: a randomized crossover (double-blind) design. Journal of the International Society of Sports Nutrition 2014 11:9.

\section{Submit your next manuscript to BioMed Central and take full advantage of:}

- Convenient online submission

- Thorough peer review

- No space constraints or color figure charges

- Immediate publication on acceptance

- Inclusion in PubMed, CAS, Scopus and Google Scholar

- Research which is freely available for redistribution

Submit your manuscript at www.biomedcentral.com/submit
C Biomed Central 